\title{
Unraveling the confusion behind hyaluronic acid efficacy in the treatment of symptomatic knee osteoarthritis
}

Larry E Miller'

Roy D Altman²

Louis F Mclntyre ${ }^{3}$

'Miller Scientific Consulting, Inc., Asheville, NC, ${ }^{2}$ Department of Rheumatology, University of California Los Angeles, Los Angeles, CA, ${ }^{3}$ Northwell Physician Partners, Sleepy Hollow, NY, USA
Correspondence: Larry E Miller Miller Scientific Consulting, Inc., 1854 Hendersonville Road, \#23I, Asheville, NC 28803, USA

Tel +l 828450 I895

Email larry@millerscientific.com
This article was published in the following Dove Press journal:

Journal of Pain Research

17 June 2016

Number of times this article has been viewed

\begin{abstract}
Hyaluronic acid (HA) is a commonly prescribed treatment for knee pain resulting from osteoarthritis (OA). Although numerous HA products have been approved for use by the US Food and Drug Administration, the efficacy of HA injections for knee OA remains disputed with meta-analyses and societal clinical guidelines drawing disparate conclusions. The American Academy of Orthopaedic Surgeons (AAOS) recently published a best-evidence systematic review and concluded that available data did not support the routine use of HA for knee OA. The purpose of the current article is to highlight issues that confound interpretation of metaanalyses on HA for knee OA, to provide realistic estimates of the true efficacy of HA injections in knee OA, and to provide commentary on the methods and conclusions from the AAOS systematic review. In general, the clinical benefit of HA is underestimated using conventional meta-analytic techniques. When accounting for differential control group effects in HA studies, it can be reasonably concluded that HA injections may be beneficial to an appreciable number of patients with knee OA. In addition, the systematic review methodology used by AAOS was questionable due to exclusion of numerous relevant studies and inclusion of studies that used HAs not approved for use in the US, both of which underestimated the true efficacy of HA injections. Overall, the efficacy of HA injections for knee OA is likely better than previously reported. Future clinical trials and meta-analyses should account for differential control group effects in order to avoid the continued confusion surrounding HA injection efficacy.
\end{abstract}

Keywords: effect size, hyaluronic acid, injection, knee, minimal important difference, osteoarthritis

Osteoarthritis (OA) of the knee is the leading cause of disability in adults ${ }^{1-3}$ and is characterized by progressive joint pain and dysfunction due to subchondral bone damage, articular cartilage loss, inflammation/synovitis, and osteophyte formation. ${ }^{4}$ Hyaluronic acid (HA) is a component of synovial fluid that acts as a joint lubricant during shear stress and a shock absorber during compressive stress. Patients with knee OA exhibit reductions in the concentration and molecular weight of endogenous HA. ${ }^{5}$ Intra-articular injection of exogenous HA replaces this deficit and stimulates production of endogenous HA, ${ }^{6}$ which may alleviate symptoms of knee OA via inhibition of chondrodegradative enzymes and inflammatory processes, stimulation of chondrocyte metabolism, and synthesis of articular cartilage matrix components. ${ }^{7}$

A number of meta-analyses on the safety and efficacy of HA for knee OA have been recently published, each using different methodology leading to different conclusions. ${ }^{8-16}$ Meta-analysis is a useful tool that involves systematic evaluation and analysis of published 
data on a specific topic to derive conclusions about that body of research. A benefit of conducting a meta-analysis is that pooling data from multiple studies allows calculation of a more precise treatment effect compared to those reported in individual studies. However, valid conclusions can only be drawn from a meta-analysis when the methodology is thorough and unbiased.

The American Academy of Orthopaedic Surgeons (AAOS) recently published a best-evidence systematic review with meta-analysis and concluded that available data did not support the routine use of HA injections for knee OA. ${ }^{17}$ In their review, the therapeutic effect of HA was expressed in "minimal important difference (MID) units", which is defined as the treatment effect observed in patients treated with HA relative to that of patients who received saline injections and then divided by the MID. However, reporting HA injection treatment effects after correcting for changes in the saline control group does not accurately reflect the treatment effect attributable to HA injections as a therapy. Unfortunately, there is no ideal control group with which to evaluate HA injections in knee OA. The clinical benefit of HA injections versus usual care would likely be overestimated and confounded by expectation bias. In addition, the clinical benefit of HA versus saline injections is likely underestimated since the therapeutic efficacy of active treatments is consistently lower when considerable treatment effects are observed in the control group, ${ }^{18,19}$ such as those observed in HA studies.

The standardized effect size (ES) is a commonly reported statistic in meta-analyses, where values of $0.2,0.5,0.8$, and 1.0 are taken to represent small, moderate, large, and very large treatment effects, respectively. ${ }^{20}$ Given that the ES associated with HA injections is $\sim 0.38$ relative to saline injections ${ }^{15,16,21}$ and that the ES for saline injections is $\sim 0.30$ relative to oral placebo, ${ }^{22}$ it is reasonable to conclude that the true ES of HA injections may be closer to 0.68 . This is considered a moderate-to-large treatment effect and is comparable to the ES of 0.60 reported for HA in patients with knee OA after adjusting for differential control group effects. ${ }^{22}$ By reasonably assuming that the true treatment effect of HA injections is closer to 0.68 (not 0.38), then the outcomes and conclusions from the AAOS systematic review can be adjusted accordingly. That is, for the highest quality trials, the more realistic treatment effect attributable to HA injections is $0.5 \mathrm{MID}$ units for visual analog scale (VAS) pain, 0.9 MID units for Western Ontario and McMaster Universities Arthritis Index function, and 0.7 MID units for Western Ontario and McMaster Universities Arthritis Index stiffness, all of which are treatment effects that "may be beneficial to an appreciable number of patients". ${ }^{23}$
In addition to these issues related to their meta-analysis, the systematic review methodology and recommendations in the AAOS report warrant further evaluation. First, eight randomized controlled trials of HA versus saline injections that met the AAOS criteria (ie, reported at least one main efficacy outcome [VAS or Western Ontario and McMaster Universities Arthritis Index subscore] and sample size $\geq 30$ per group) were not included in this systematic review. ${ }^{24-31}$ It would be helpful to understand if these studies were considered for inclusion and, if so, the reason for their exclusion. In a previous meta-analysis, ${ }^{16}$ the treatment effect reported in these eight studies was 2.5-fold greater compared to the remaining studies, suggesting that exclusion of these studies may have significantly underestimated the clinical benefit of HA injections. Second, given that HAs approved for use in the US are considerably more efficacious than non-approved $\mathrm{HAs}^{16}$ and since the systematic review in question was commissioned by the AAOS, the inclusion of studies using HAs that are not available in the US is questionable. Finally, it is perplexing that the AAOS does not recommend HA injections for symptomatic knee OA citing lack of efficacy, but it does recommend nonsteroidal anti-inflammatory drugs. ${ }^{32}$ This is despite numerous reports that HA injections are safe and that efficacy of HA is at least comparable, if not superior, to that of nonsteroidal anti-inflammatory drugs. ${ }^{16,33-35}$

In summary, mounting evidence suggests that HA injections for knee OA are more efficacious than previously reported. Future clinical trials and meta-analyses should be designed to account for differential control group effects in order to avoid the continued confusion surrounding HA injection efficacy.

\section{Disclosure}

RDA has served as a consultant to McNeil, Ferring, and QMed. LEM and LFM report no conflicts of interest in this work.

\section{References}

1. Felson DT, Naimark A, Anderson J, Kazis L, Castelli W, Meenan RF. The prevalence of knee osteoarthritis in the elderly. The Framingham Osteoarthritis Study. Arthritis Rheum. 1987;30(8):914-918.

2. van Saase JL, van Romunde LK, Cats A, Vandenbroucke JP, Valkenburg HA. Epidemiology of osteoarthritis: Zoetermeer survey. Comparison of radiological osteoarthritis in a Dutch population with that in 10 other populations. Ann Rheum Dis. 1989;48(4):271-280.

3. Peat G, McCarney R, Croft P. Knee pain and osteoarthritis in older adults: a review of community burden and current use of primary health care. Ann Rheum Dis. 2001;60(2):91-97.

4. Dieppe PA, Lohmander LS. Pathogenesis and management of pain in osteoarthritis. Lancet. 2005;365(9463):965-973.

5. Dahl LB, Dahl IM, Engstrom-Laurent A, Granath K. Concentration and molecular weight of sodium hyaluronate in synovial fluid from patients with rheumatoid arthritis and other arthropathies. Ann Rheum Dis. 1985;44(12):817-822. 
6. Smith MM, Ghosh P. The synthesis of hyaluronic acid by human synovial fibroblasts is influenced by the nature of the hyaluronate in the extracellular environment. Rheumatol Int. 1987;7(3):113-122.

7. Goldberg VM, Buckwalter JA. Hyaluronans in the treatment of osteoarthritis of the knee: evidence for disease-modifying activity. Osteoarthritis Cartilage. 2005;13(3):216-224.

8. Sadabad HN, Behzadifar M, Arasteh F, Behzadifar M, Dehghan HR. Efficacy of platelet-rich plasma versus hyaluronic acid for treatment of knee osteoarthritis: a systematic review and meta-analysis. Electron Physician. 2016;8(3):2115-2122.

9. Wang F, He X. Intra-articular hyaluronic acid and corticosteroids in the treatment of knee osteoarthritis: a meta-analysis. Exp Ther Med. 2015;9(2):493-500.

10. Bannuru RR, Vaysbrot EE, Sullivan MC, McAlindon TE. Relative efficacy of hyaluronic acid in comparison with NSAIDs for knee osteoarthritis: a systematic review and meta-analysis. Semin Arthritis Rheum. 2014;43(5):593-599.

11. Miller LE, Block JE. US-approved intra-articular hyaluronic acid injections are safe and effective in patients with knee osteoarthritis systematic review and meta-analysis of randomized, saline-controlled trials. Clin Med Insights Arthritis Musculoskelet Disord. 2013;6:57-63.

12. Colen S, van den Bekerom MP, Mulier M, Haverkamp D. Hyaluronic acid in the treatment of knee osteoarthritis: a systematic review and meta-analysis with emphasis on the efficacy of different products. BioDrugs. 2012;26(4):257-268.

13. Bannuru RR, Natov NS, Dasi UR, Schmid CH, McAlindon TE. Therapeutic trajectory following intra-articular hyaluronic acid injection in knee osteoarthritis--meta-analysis. Osteoarthritis Cartilage. 2011;19(6):611-619.

14. Bannuru RR, Natov NS, Obadan IE, Price LL, Schmid CH, McAlindon TE. Therapeutic trajectory of hyaluronic acid versus corticosteroids in the treatment of knee osteoarthritis: a systematic review and meta-analysis. Arthritis Rheum. 2009;61(12):1704-1711.

15. Rutjes AW, Juni P, da Costa BR, Trelle S, Nuesch E, Reichenbach S. Viscosupplementation for osteoarthritis of the knee: a systematic review and meta-analysis. Ann Intern Med. 2012;157(3):180-191.

16. Strand V, McIntyre LF, Beach WR, Miller LE, Block JE. Safety and efficacy of US-approved viscosupplements for knee osteoarthritis: a systematic review and meta-analysis of randomized, saline-controlled trials. J Pain Res. 2015;8:217-228.

17. Jevsevar D, Donnelly P, Brown GA, Cummins DS. Viscosupplementation for osteoarthritis of the knee: a systematic review of the evidence. J Bone Joint Surg Am. 2015;97(24):2047-2060.

18. Lund K, Vase L, Petersen GL, Jensen TS, Finnerup NB. Randomised controlled trials may underestimate drug effects: balanced placebo trial design. PLoS One. 2014;9(1):e84104.

19. Fountoulakis KN, Moller HJ. Antidepressant drugs and the response in the placebo group: the real problem lies in our understanding of the issue. J Psychopharmacol. 2012;26(5):744-750.

20. Cohen J. Statistical Power Analysis for the Behavioral Sciences. Hillside, NJ: Lawrence Erlbaum Associates; 1987.

21. American Academy of Orthopaedic Surgeons [webpage on the Internet]. Treatment of Osteoarthritis of the Knee: Evidence-Based Guideline. 2013. Available from: http://www.aaos.org/research/guidelines/TreatmentofOsteoarthritisoftheKneeGuideline.pdf. Accessed April 15, 2016
22. Bannuru RR, McAlindon TE, Sullivan MC, Wong JB, Kent DM, Schmid CH. Effectiveness and implications of alternative placebo treatments: a systematic review and network meta-analysis of osteoarthritis trials. Ann Intern Med. 2015;163(5):365-372.

23. Johnston BC, Thorlund K, Schunemann HJ, et al. Improving the interpretation of quality of life evidence in meta-analyses: the application of minimal important difference units. Health Qual Life Outcomes. 2010;8:116.

24. Brandt KD, Block JA, Michalski JP, Moreland LW, Caldwell JR, Lavin PT. Efficacy and safety of intraarticular sodium hyaluronate in knee osteoarthritis. ORTHOVISC Study Group. Clin Orthop Relat Res. 2001;(385):130-143.

25. Jorgensen A, Stengaard-Pedersen K, Simonsen O, et al. Intra-articular hyaluronan is without clinical effect in knee osteoarthritis: a multicentre, randomised, placebo-controlled, double-blind study of 337 patients followed for 1 year. Ann Rheum Dis. 2010;69(6):1097-1102.

26. Lohmander LS, Dalen N, Englund G, et al. Intra-articular hyaluronan injections in the treatment of osteoarthritis of the knee: a randomised, double blind, placebo controlled multicentre trial. Hyaluronan Multicentre Trial Group. Ann Rheum Dis. 1996;55(7):424-431.

27. Puhl W, Bernau A, Greiling H, et al. Intra-articular sodium hyaluronate in osteoarthritis of the knee: a multicenter, double-blind study. Osteoarthritis Cartilage. 1993;1(4):233-241.

28. Rolf CG, Engstrom B, Ohrvik J, Valentin A, Lilja B, Levine DW. A comparative study of the efficacy and safety of hyaluronan viscosupplements and placebo in patients with symptomatic and arthroscopy-verified cartilage pathology. J Clin Res. 2005;8:15-32.

29. Wobig M, Dickhut A, Maier R, Vetter G. Viscosupplementation with hylan G-F 20: a 26-week controlled trial of efficacy and safety in the osteoarthritic knee. Clin Ther. 1998;20(3):410-423.

30. Altman RD, Akermark C, Beaulieu AD, Schnitzer T; Durolane International Study Group. Efficacy and safety of a single intra-articular injection of non-animal stabilized hyaluronic acid (NASHA) in patients with osteoarthritis of the knee. Osteoarthritis Cartilage. 2004;12(8): 642-649.

31. Petrella RJ, Cogliano A, Decaria J. Combining two hyaluronic acids in osteoarthritis of the knee: a randomized, double-blind, placebocontrolled trial. Clin Rheumatol. 2008;27(8):975-981.

32. Surgeons AAoO [webpage on the Internet]. Treatment of Osteoarthritis of the Knee: Evidence-Based Guideline. 2nd ed. 2013. Available from: http://www.aaos.org/uploadedFiles/PreProduction/Quality/Guidelines_and_Reviews/Osteoarthritis\%20of\%20the \%20Knee $\% 20-\% 20$ non-arthroplasty.pdf. Accessed April 15, 2016.

33. Campbell KA, Erickson BJ, Saltzman BM, et al. Is local viscosupplementation injection clinically superior to other therapies in the treatment of osteoarthritis of the knee: a systematic review of overlapping metaanalyses. Arthroscopy. 2015;31(10):2036.e14-2045.e14.

34. Bannuru RR, Schmid CH, Kent DM, Vaysbrot EE, Wong JB, McAlindon TE. Comparative effectiveness of pharmacologic interventions for knee osteoarthritis: a systematic review and network meta-analysis. Ann Intern Med. 2015;162(1):46-54.

35. McAlindon TE, Bannuru RR, Sullivan MC, et al. OARSI guidelines for the non-surgical management of knee osteoarthritis. Osteoarthritis Cartilage. 2014;22(3):363-388.
Journal of Pain Research

\section{Publish your work in this journal}

The Journal of Pain Research is an international, peer reviewed, open access, online journal that welcomes laboratory and clinical findings in the fields of pain research and the prevention and management of pain. Original research, reviews, symposium reports, hypothesis formation and commentaries are all considered for publication.
The manuscript management system is completely online and includes a very quick and fair peer-review system, which is all easy to use. Visit http://www.dovepress.com/testimonials.php to read real quotes from published authors. 